\title{
Com a mão fundo no coração das marionetas
}

\author{
Rui Aires Augusto
}
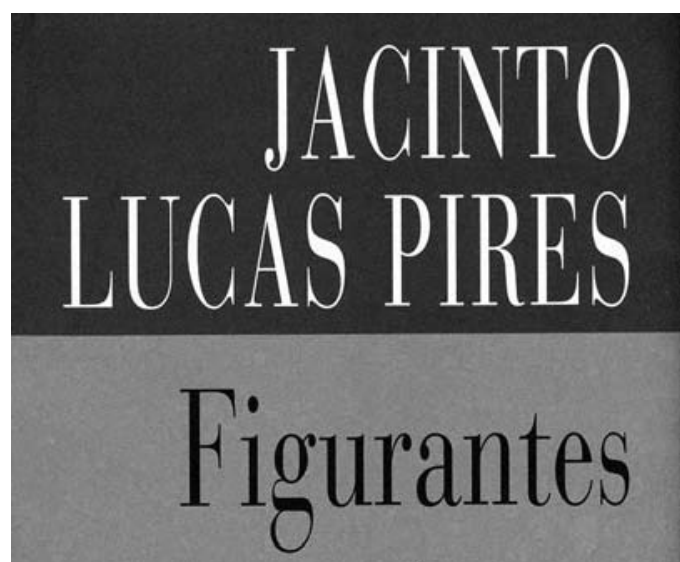

e outras peças

TEATRO
Jacinto Lucas Pires, Figurantes e outras peças, Lisboa, Edições Cotovia, 2004, 263 pp.

E decido fazê-lo por recortes, atendendo a variações também elas presentes no texto, avançando algumas hipóteses, isolando alguns elementos de significação.

"sete personagens tentam vencer o medo do escuro" e "um intermediário que ajuda a vencer o tempo" Sob o pretexto de um motivo (uma mão que aparece a um homem magro através de uma abertura para o exterior), sete personagens que esperam entretêm-se a fazer circular uma narrativa, um "pensamento" sugerido por uma delas e apercebido pelas outras, por uma certa forma de telepatia. No início titubeante, não aderido, desconfiado, esse motivo dá razão ao encontro - sete personagens que esperam e interagem, que falam, não só de si, mas animadas por algum debate (o que é dizer um tema) que pede participação, e que surge, por outro lado, como forma de regulação do circuito comunicacional.

Esta é uma situação repetida na obra de Jacinto Lucas Pires $^{3}$ : a partir de um dado contexto, os interlocutores operam as suas variações, constroem-se. Cedo percebemos o autor pedindo um corpo na ficção para se fazer passar por Hidra de muitas cabeças capazes de imaginações múltiplas, simultâneas. Não o faz às claras, é certo. Antes se esconde numa realidade fragmentada pelas várias personagens, dispersando esse motivo por elas de acordo com as suas fantasias pessoais, como se num documentário se pudesse reunir uma colecção de depoimentos que nos são apresentados numa espécie de zapping.

Nessa simultaneidade de planos, nesse entrelaçado de variações, entrevemos o jogo da construção das personagens através do recorte e inscrição de discursos, com os quais podem ganhar um caso particular, um sentido do mundo, uma biografia. A princípio figurantes da imaginação do autor, essas entidades ocupam-se a dar voz a uma história imaginada por si; depois a suspeitar dela, a criticá-la, a desconstruí-la para impor a sua variação, recortando-se do motivo, isolando-se.

Seria inevitável que a situação original, ou a sua orientação, pudesse gerar, nesses termos, situações de contraste, discordância, contradições; seria inevitável que fugisse ao controlo do mediador. Porque estas são personagens costuradas a partir de recortes de discursos em jeito de confissão: assim que ganham alguma textura, parece que logo escapam à linha com que o autor as queria coser de enfiada, alinhavadas num motivo. Como seria possivel
In Programa do PoNTI'04 / XIII Festival da UTE, Porto TNSJ, p. 12.

2Para a informação completa da ficha técnica deste espectáculo, consulte-se, na entrada "Figurantes", a CETBase base de dados de espectáculos em Portugal do Centro de Estudos de Teatro da Universidade de Lisboa (www.fl.ul.pt/centro estudos-teatro.htm) convocar algumas interrogações, para iniciar uma leitura. 
cento e seis

Sinais de cena 3.2005 $\mid$ Leituras

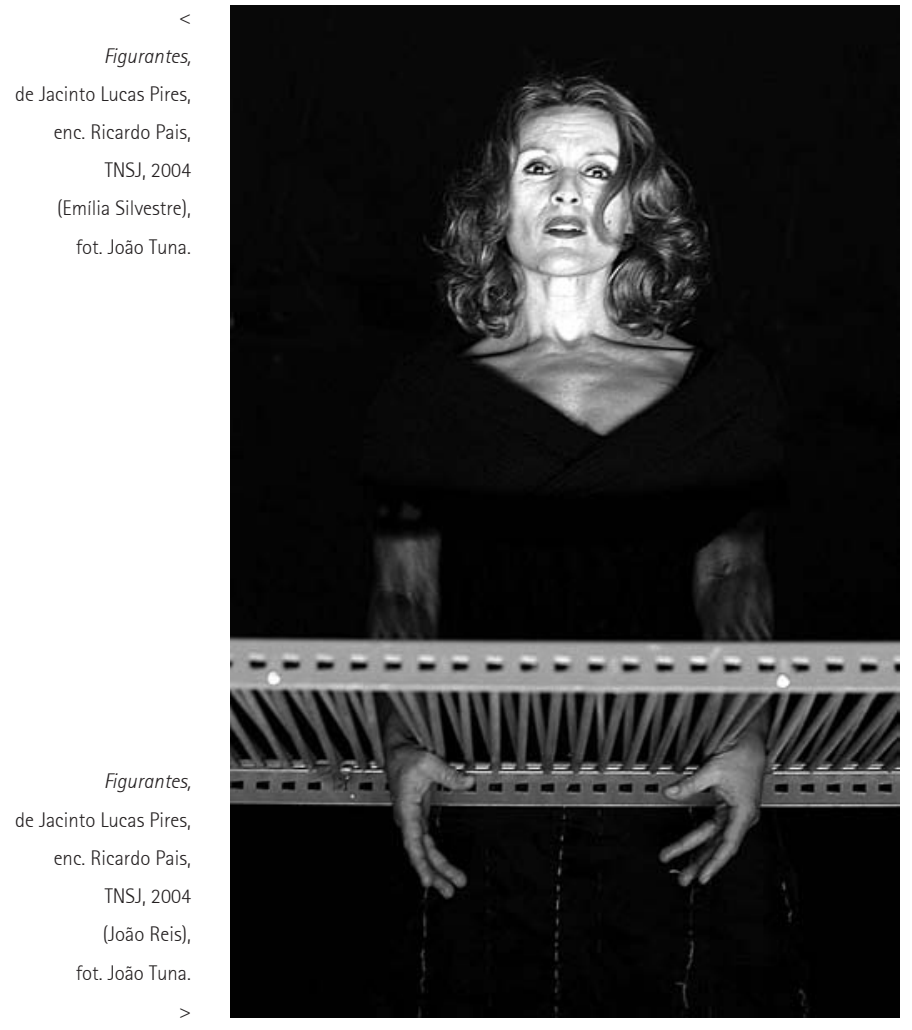

fazer alinhar a multiplicidade, a dissolvência, através de uma linha narrativa sempre em movimento, repleta de peripécias e de abandonos, cuja particularidade é ser circular e progressiva, no sentido de ser invariavelmente recuperada e reformulada constantemente? Percebemo-la então como cena a desfazer e a refazer. Pontuada e pontual, ela é o interruptor off de uma situação aparentemente vazia, mas que é a situação de base, que é a necessidade de fazer jogar, fazer interagir aquelas sete personagens, tornando-se interruptor on do jogo. 0 perigo, ou a intenção (qual é o efeito que o traduz melhor?), é a possibilidade de desapropriação, por uma capacidade de presença e testemunho, como se quisessem fazer crer que estiveram lá e viram, que foram figurantes.

Esse motivo recosido pela transacção de passados, através de uma derivação elíptica de incisões recuperadas de mais atrás no tempo, constrói-se a partir daí como narrativa nova, como uma aposta no valor sincrónico, na simultaneidade, como forma de os figurantes pertencerem aí. 0 passado, este novo passado, progride por hipóteses, como um regresso e esclarecimento, como o apuramento da verdade. É este o efeito - uma memória em construção.

"culpas e violentas fantasias de toda aquela gente comum"

${ }^{4}$ Sobre o conceito "polilogo", ou "monólogo a várias vozes", consultese Anne Ubersfeld (1996: 63). Para uma melhor contextualização deste

conceito, consulte-se ainda Jean-Pierre Sarrazac (2002: 163-64), e a ideia

de "uso polifónico" (ibidem: 145).
No entanto, esse alinhavado de recortes de discursos não é composto linearmente. A história do homem magro não avança sem sobressaltos. Faz-se nos intervalos do registo comunicacional a que se entregam as personagens, é por vezes a não se ajustar, preferindo ignorar-se, passar por cima, ou responder-se mais à frente. Ao serem recortados e recosidos, deslocados, dispersos, esses discursos passam a ser tratados como objecto, servem uma estratégia de "espectacularização da linguagem" (cf. Sarrazac 2002:149), através da incrustação de discursos que não se respondem, recuperada entre a sucessão de pseudo-réplicas que tendem

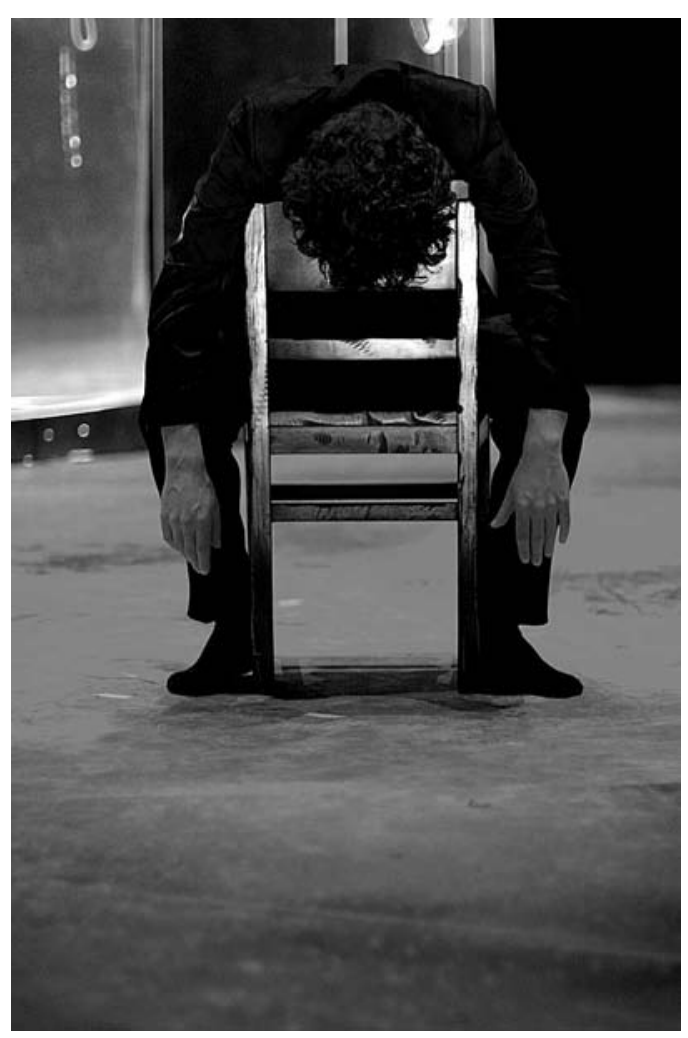

quase se anulam, através da variação de um contexto, de incorrecções deliberadas ou excreções de linguagem, que agridem pelo absurdo (recupero do autor o termo "plimplezas", p. 93), ou, por outro lado, de uma linguagem exuberante, poética.

A certa altura perguntamo-nos: podem estas personagens entregar-se a um solilóquio a várias vozes, pelo menos naqueles momentos em que, através do recorte e montagem dos seus discursos, reinventam a fábula, admitindo, porém, uma atitude interrogadora e contraditória em relação a si mesmas? Ou poderiam ser os portadores do monólogo interior do autor, reeditando uma espécie de "corrente de consciência" parcialmente decalcada e adaptada do Ulisses, de James Joyce, como se a virtude de ser personagem fosse a sua capacidade de se rememorar? Poderia adivinhar-se naquela história com o motivo da mão a dinâmica de um "polílogo", as personagens reduzidas a recitadores de ideologia ou a declamadores, à imagem de (A)tentados, de Martin Crimp, reinventando agora e continuamente essa fábula a desfazer para refazer, situação em que o autor se vê desmultiplicado e em que as personagens surgem anuladas para se imporem como refracções do contador da história? Ou elas mesmas contadoras da sua história particular, para a qual aproveitam um contexto que surge na conversa para introduzirem a sua variação?

0 processo de criação dessa história pode ele próprio ser uma duplicação do acto criador da escrita, em que o autor duvida, questiona, consulta? Ou até mesmo o gesto da leitura, da mesma forma criador, entendido como reescrita? Chegado ai, o autor resistiria, poderia impor uma peripécia, uma nova orientação, redefinindo a situação quando já quase tudo parece fácil de ser identificado pelo leitor, quando este já participa, projectando os seus fantasmas, apropriando-se daquela biografia disponivel, moldando-a ao seu caso pessoal. E aí o autor afasta-se, desinveste toda a possibilidade de identificação com o papel de protagonista. 


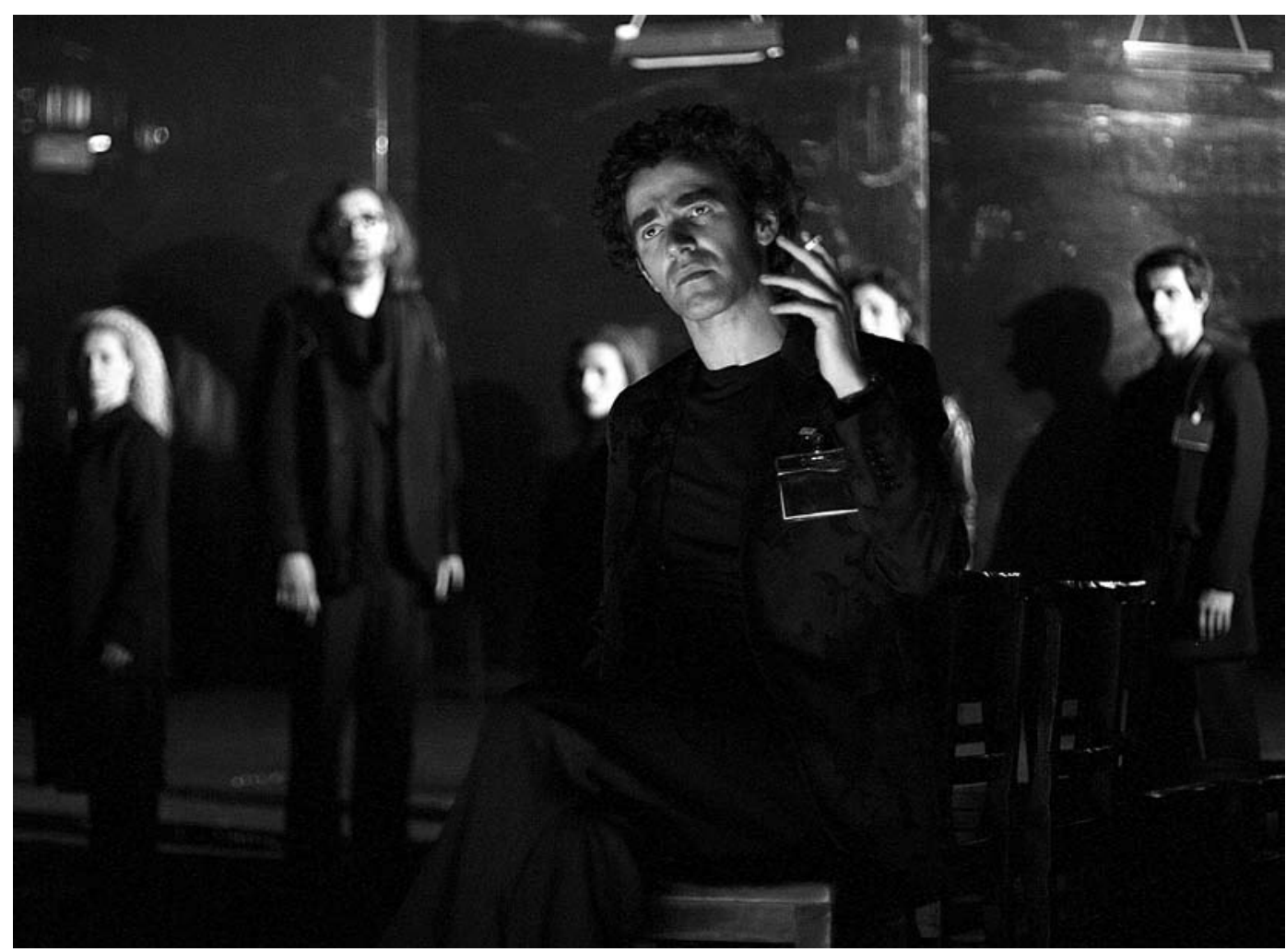

Figurantes, de Jacinto Lucas Pires, enc. Ricardo Pais, TNSJ, 2004 (João Reis e, ao fundo, Luisa Cruz, António Durães, Emilia Silvestre, Micaela Cardoso e Pedro Almendra), fot. João Tuna.

"onde estão, onde estamos" e "carregados da memória da representação"

E onde está o conflito? 0 conflito dilui-se nesses pequenos gestos de agressão em que os recortes dos discursos, numa pulsão verborreica, se sucedem, se sobrepõem, em que as personagens ganham textura e querem construir-se à força da desapropriação de uma biografia que não é, mas que pode ser a sua.

0 conflito dilui-se na estruturação de um espaço, aparentemente vazio, deserto, mas múltiplo, como uma caixa chinesa que mostra a ilusão de vários compartimentos, uma espécie de huis-clos poliédrico ou casa de espelhos em que há portas que conduzem a nenhum lugar. 0 lugar efectivo onde estão, espaço fechado, de agressão latente (luzes fortes), é a lembrança de um não-lugar, um deserto, um não-destino, que estabelece esse lugar como uma cristalização no tempo e no espaço.

Pode tornar-se um espaço de debandada como se a entrada de duas outras personagens, numa aparição fantasmagórica, pontual, resolvida em canibalismo, tivesse a força simbólica de um espantalho que afugentasse as aves e interrompesse o transbordamento pelas várias latitudes da fábula, demovendo a possibilidade de uma significação que se construia com o retorno ao microcosmo da situação original vazia.

Precisamente, e porque está implicada uma dissociação do espaço jogada em dois andamentos/momentos, esse macrocosmo criado, verdadeiro nicho de mundos paralelos, torna-se um lugar pseudo-refúgio, um não-lugar ou um lugar psicológico, construído pela memória, lugar de apropriação, primeiro de povoamento, de conglomerado, depois de participação e partilha.

0 conflito dilui-se, enfim, na clausura de um espaço que é nenhures, na clausura de uma espera de nada, na dicotomia dos espaços.

$E$, no entanto, um final de choque, um final perturbador que desmascara toda a artificialidade que o teatro pode criar, a ficção dos dias, um mundo virtual que propõe sempre interlocutores virtuais, que dispõe de luzes ilusórias, um teatro que se alimenta de pedaços de vida(s), (reedição) de obras, de autores, como se o canibalismo lhe servisse como metáfora da apropriação - intertextual, biográfica, identitária. Sabemos então que há um espaço real que alimenta estes espaços virtuais: a projecção de uma sala de ensaios onde as personagens comparecem com os discursos decorados para uma audição em tempo real.

Todos esses efeitos de teatro... 0 que pode ser real quando é tudo virtual? E a máscara do autor, sempre e sobretudo, com a mão fundo no coração da marionetas.

\section{Referências bibliográficas}

CRIMP, Martin (2000), Peça com repetições / (A)tentados, trad. e introdução de Paulo Eduardo Carvalho, Porto, Campo das Letras.

JOYCE, James (2003), Ulisses, trad. e notas de João Palma-Ferreira, Lisboa, Livros do Brasil.

LUCAS PIRES, Jacinto (2002), Escrever, falar, Lisboa, Edições Cotovia.

--(2004), Figurantes e outras peças, Lisboa, Edições Cotovia.

SARRAZAC, Jean-Pierre (2002), o futuro do drama: Escritas dramáticas contemporâneas, trad. Alexandra Moreira da Silva, Porto, Campo das Letras.

UBERSFELD, Anne (1996), Lire le Théâtre III - Le Dialogue de Théâtre, Paris, Éditions Belin. 